\title{
Campylobacter pylori is not Associated with Gastroparesis
}

\author{
JEFFREY L. BARNETT, MD, ELIZABETH M. BEHLER, HENRY D. APPELMAN, MD, and \\ GRACE H. ELTA, MD
}

\begin{abstract}
There is a high incidence of Campylobacter pylori in the gastric mucosa of patients with duodenal ulcer, gastric ulcer, and nonulcer dyspepsia. Factors that lead to development of this infection are unknown. We hypothesized that delayed solid-phase gastric emptying, a condition characterized by antral stasis, might predispose to Campylobacter pylori infection. We prospectively studied 51 patients with symptoms of gastroparesis using a solid-phase gastric emptying study and upper endoscopy. Patients were excluded if they had predominant symptoms of epigastric pain or an abnormal endoscopy. Three biopsies were obtained from the antrum and stained with $H \& E$. When any inflammation was present, a Warthin-Starry stain was also performed. These were blindly examined for chronic inflammation, activity, and presence of Campylobacter pylori. Campylobacter pylori was not more common in patients with gastroparesis, documented by delayed gastric emptying, than in patients with a normal emptying study. On the contrary, there was a significantly lower incidence of Campylobacter pylori in those with delayed emptying compared to those with normal emptying (5\% vs $31 \%, \mathrm{P}<0.05$ ). Gastritis activity correlated closely with Campylobacter presence. Inactive chronic gastritis with Campylobacter was equally common in those with delayed or normal gastric emptying. Diabetics were no more likely to harbor Campylobacter pylori than nondiabetics (16\% vs 25\%). The 5\% incidence of Campylobacter in the gastroparesis group is less than, but approaches, that previously reported in asymptomatic controls. The $31 \%$ incidence of Campylobacter in the group with symptoms of gastroparesis but normal gastric emptying approaches that reported for nonulcer dyspepsia. Our data suggest that gastroparesis does not predispose to Campylobacter pylori infection or histologic chronic gastritis.
\end{abstract}

KEY WORDS: Campylobacter pylori; gastroparesis; gastritis; diabetes mellitus.

Campylobacter pylori (CP) is a spiral-shaped bacterium found in gastric mucosa in association with gastritis and peptic ulcer disease $(1,2) .{ }^{1}$ The gastric antrum appears to be the predominant site of $\mathrm{CP}$ infection (1). However, the pathogenesis and pre-

\footnotetext{
Manuscript received August 16, 1988; revised manuscript received May 31, 1989; accepted June 12, 1989.

From the Departments of Internal Medicine and Pathology, University of Michigan, Ann Arbor, Michigan.

Presented in part at the American Gastroenterological Association, New Orleans, May 1988.

Address for reprint requests: Dr. Jeffrey Barnett, University of Michigan Hospital, Gastroenterology, 3912 Taubman Center, Ann Arbor, Michigan 48109-0362.
}

disposing factors to development of this infection are unclear. Recent reports have suggested an increased incidence of this organism in gastroesophageal reflux disease, which may be associated with gastric dysmotility (3-5). The incidence of $\mathrm{CP}$ in gastroparesis is unknown. We hypothesized that antral gastric stasis might predispose to diminished mucosal defense and/or bacterial overgrowth and that $\mathrm{CP}$ would be likely to occur in this setting. In an effort to better understand the pathogenesis of CP infection, we studied the incidence of this organism in symptomatic patients with delayed solidphase gastric emptying compared to a population 
BARNETT ET AL

with similar symptoms but normal gastric emptying. We excluded patients with mucosal erosions or ulcers because of the already well-documented high incidence of $\mathrm{CP}$ in peptic ulcer disease.

\section{MATERIALS AND METHODS}

Patients seen in the gastroenterology clinic over a 16-month period with symptoms of gastroparesis for at least three months were studied. These symptoms included nausea, vomiting, upper abdominal discomfort, early satiety, bloating, and anorexia. Only patients who had completed a solid-phase emptying study ordered at the discretion of their attending physician were evaluated. An esophagogastroduodenoscopy (EGD) was first routinely performed to rule out the possibility of obstruction or peptic ulcer disease. Patients with mucosal erosions, ulcers, or gross hemorrhages were excluded. Normal mucosa or mild erythema was accepted. Other exclusions included prior gastric surgery, antibiotic or bismuth ingestion within the past three months, chronic nonsteroidal antiinflammatory drug use ( $>5$ tablets per month) or even episodic use of these drugs in the past six weeks, and symptoms of upper abdominal discomfort alone.

A solid-phase gastric emptying study was performed within 2 weeks and usually within a few days of the EGD. After an overnight fast, a standard meal of toast and technetium-labeled egg was consumed. Scintigraphic images were obtained and percent meal remaining calculated at $15,30,45,60$, and $120 \mathrm{~min}$. Greater than $52 \%$ activity at $120 \mathrm{~min}$ was considered abnormal. During EGD, three random antral biopsies were obtained and stained with hematoxylin and eosin. In all biopsies with any inflammation, a Warthin-Starry stain was also examined. Biopsies were read blindly without knowledge of gastric emptying status and scored on the severity of chronic inflammation defined as plasmacytosis in the lamina propria $(0=$ normal, $1=$ focal superficial involving only the pit compartment, 2 = diffuse superficial, $3=$ extension into the middle of the glandular compartment, 4 $=$ transmucosal), presence or absence of activity defined as PMNs in the epithelium, and presence or absence or $\mathrm{CP}$. The biopsies were too superficial to comment on the presence of atrophy.

\section{RESULTS}

Fifty-one patients with symptoms of gastroparesis were identified. Their mean age was 38 years (range 21-81 years), 75\% were women and 37\% were diabetic. The 19 patients with diabetes had their disease for a mean duration of 17 years (range $0.5-42$ years). Fifteen patients $(79 \%)$ had type I disease, $17(89 \%)$ take insulin regularly, and 11 (58\%) suffer from symptomatic complications of retinopathy and/or nephropathy. Delayed gastric emptying was found in $37 \%$ of the patients (Table 1). Over $50 \%$ of these patients with delayed empty-
Table 1. Patient Characteristics

\begin{tabular}{lcc}
\hline & \multicolumn{2}{c}{ Gastric emptying } \\
\cline { 2 - 3 } & Delayed & Normal \\
\hline Patients $(N)$ & 19 & 32 \\
Age (years, mean) & 33 & 41 \\
Sex (M:F) & $5: 14$ & $8: 24$ \\
Diabetes $(\%)$ & 53 & 28 \\
\hline
\end{tabular}

ing had diabetes mellitus. Other diagnoses included idiopathic gastroparesis and gastroparesis secondary to scleroderma. Patients with gastroparesis symptoms but normal gastric emptying were diagnosed with nonulcer dyspepsia, irritable bowel syndrome, possible diabetic gastroparesis, anxiety disorder, or upper gastrointestinal symptoms of unclear etiology. CP was found in $31 \%$ of those with normal gastric emptying but in only $5 \%$ of those with delayed gastric emptying $(P<0.05$ two-tailed Fischer's exact test) (Table 2). Activity in the gastritis correlated exactly with the presence of $\mathrm{CP}$ except in one case where active gastritis was found without CP. Chronic gastritis with a score of 2 or more was seen approximately twice as often in the group with normal gastric emptying than in those with delayed gastric emptying. The small incidence of inactive chronic gastritis without $\mathrm{CP}$ was similar in both groups. The incidence of $\mathrm{CP}$ and gastritis was also compared in diabetics and nondiabetics (Table 3). No significant difference was noted in active chronic gastritis, inactive chronic gastritis, and $\mathrm{CP}$ presence between the two groups whether they had normal or delayed gastric emptying.

\section{DISCUSSION}

The pathogenesis of CP infection is unknown. Recent evidence suggests that person-to-person transmission occurs $(6,7)$. Presumably, the organism is "ingested" and subsequently colonizes the gastric mucosa. CP has been identified in the stom-

TABle 2. Gastric Emptying and InCIDENCE OF Gastritis AND CAMPYLOBACTER PYLORI

\begin{tabular}{llr}
\hline & \multicolumn{2}{c}{ Gastric emptying } \\
\cline { 2 - 3 } & $\begin{array}{c}\text { Delayed } \\
(\mathrm{N}=19)\end{array}$ & $\begin{array}{c}\text { Normal } \\
(\mathrm{N}=32)\end{array}$ \\
\hline Chronic gastritis (score $\geq 2)$ & $4(21 \%)$ & $14(44 \%)$ \\
Campylobacter Pylori & $1(5 \%)^{*}$ & $10(31 \%)$ \\
Active gastritis & $1(5 \%)^{*}$ & $11(34 \%)$ \\
Inactive gastritis without CP & $3(16 \%)$ & $3(16 \%)$ \\
\hline
\end{tabular}

*(P<0.05 two tailed Fischer's exact test $)$. 
Table 3. Diabetes and InCIDENCE of Gastritis and CampYlobacter Pylori

\begin{tabular}{lccccc}
\hline & \multicolumn{2}{c}{ Diabetics $(\mathrm{N}=19)$} & & \multicolumn{2}{c}{ Nondiabetics $(\mathrm{N}=32)$} \\
\cline { 2 - 3 } & Delayed emptying & Normal emptying & & Delayed emptying & Normal emptying \\
\hline Chronic Gastritis (Score $\geq 2)$ & $2 / 10(20 \%)$ & $4 / 9(44 \%)$ & $2 / 9(22 \%)$ & $10 / 23(43 \%)$ \\
Campylobacter pylori & $0 / 10(0 \%)$ & $3 / 9(33 \%)$ & & $1 / 9(11 \%)$ & $7 / 23(30 \%)$ \\
Active gastritis & $0 / 10(0 \%)$ & $3 / 9(33 \%)$ & & $1 / 9(11 \%)$ & $8 / 23(35 \%)$ \\
Inactive gastritis without CP & $2 / 10(20 \%)$ & $1 / 9(11 \%)$ & & $1 / 9(11 \%)$ & $2 / 23(9 \%)$ \\
\hline
\end{tabular}

ach and in the metaplastic gastric surface mucosa in the esophagus and duodenal bulb, but the predominant site is the gastric antrum (8). When the organism is identified from gastric metaplastic tissue near a duodenal ulcer, it is present in the antral mucosa as well (9). It has been hypothesized that CP primarily colonizes the antrum and spreads distally to infect gastric metaplastic tissue of the inflamed duodenal bulb, eventually contributing to frank ulceration. Unfortunately, the factors that predispose to colonization of the gastric antrum are unknown. The incidence of $\mathrm{CP}$ infection increases with advanced age, but conditions that predispose the elderly to this infection have not yet been elucidated (10). It has been demonstrated that gastric emptying slows with aging, suggesting a possible correlation between slowed gastric emptying and $\mathrm{CP}$ infection (11). In addition, recent studies show a high prevalence of $\mathrm{CP}$ in patients with nonulcer dyspepsia and gastroesophageal reflux disease (3-5). Since delayed gastric emptying may be a common feature of these conditions, we hypothesized that antral stasis may be an important factor which predisposes to $\mathrm{CP}$ infection. We did not find this to be true. On the contrary, patients with delayed solid-phase gastric emptying had significantly lower incidence of CP infection than those with similar symptoms and normal emptying. The low incidence of $\mathrm{CP}$ in our patients with documented gastroparesis is less than, but approaches, that reported in the asymptomatic normal population $(4,12,13)$. On the other hand, our population with gastroparesis-like symptoms but normal gastric emptying had an incidence of $\mathrm{CP}$ approaching that previously reported in nonulcer dyspepsia (3, 4). Marshall believes that symptoms of nonulcer dyspepsia are related to infection with CP $(14,15)$. Our normal gastric emptying group may simply reflect a nonulcer dyspepsia population. Alternatively, the delayed gastric emptying group had a low incidence of CP because their symptoms are likely caused by poor gastric emptying. Of course, these results reflect a heterogeneous referred population examined with nuclear gastric emptying studies, although we believe that similar results would be found in any population of patients with gastroparesis symptoms. Two recent studies reported in abstract form have evaluated the possibility that $\mathrm{CP}$ infection may cause delayed gastric emptying (16, 17). Both reports found no increased incidence of delayed gastric emptying in nonulcer dyspepsia patients with $\mathrm{CP}$ compared to those without the organism. Although these studies explored the issue in a reverse manner from this study, they confirm the lack of association between CP and delayed gastric emptying.

We conclude that gastroparesis is not related to $\mathrm{CP}$ infection and that antral stasis does not predispose to infection with this organism.

\section{ACKNOWLEDGMENT}

The authors thank Ms. Debra Myus for secretarial assistance.

\section{REFERENCES}

1. Warren JR, Marshall B: Unidentified curved bacilli on gastric epithelium in active chronic gastritis. Lancet 2:12731275,1983

2. Marshall BJ, Warren JR: Unidentified curved bacilli in the stomach of patients with gastritis and peptic ulceration. Lancet 1:1311-1314, 1984

3. Marshall BJ, McGechie DB, Rogers PA, Glancy RJ: Pyloric Campylobacter infection and gastroduodenal disease. Med J Aust 142:439-444, 1985

4. Pettross CW, Cohen H, Appelman MD, Valenzuela JE, Chandrasoma P: Campylobacter pyloridis: Relationship to peptic disease, gastric inflammation and other conditions. Gastroenterology 90:1585, 1986 (abstract)

5. Humphries H, Dooley C, O'Leary D, et al: Effect of therapy on Campylobacter pyloridis: A randomized trial. Gut 27:A611, 1986 (abstract)

6. Berkowicz J, Lee A: Person-to-person transmission of Campylobacter pylori Lancet 2:680-1, 1987 (letter)

7. Mitchell HM, Bohane TD, Berkowicz J, Hazell SL, Lee A: Antibody to Campylobacter pylori in families of index children with gastrointestinal illness due to $C$. pylori. Lancet 2:681-682, 1987 (letter) 
8. Goodwin CS, Armstrong JA, Marshall BJ: Campylobacter pyloridis, gastritis, and peptic ulceration. J Clin Pathol 39:353-365, 1986

9. Wyatt JI, Rathbone BJ, Dixon MF, Heatley RV: Campylobacter pyloridis and acid induced gastric metaplasia in the pathogenesis of duodenitis. J Clin Pathol 40:841-848, 1987

10. Graham DY, Klein PD, Opekun AR, Alpert LC, et al: Epidemiology of Campylobacter pyloridis infection. Gastroenterology 90:1411, 1987 (abstract)

11. Moore JG, Tweedy C, Christian PE, Datz FL: Effect of age on gastric emptying of liquid-solid meals in man. Dig Dis Sci 28:340-344, 1983

12. Longenberg ML, Tytgat GN, Schipper ME, Rietra PJ, Zanen HC: Campylobacter-like organisms in the stomach of patients and healthy individuals. Lancet 1:1348-1349, 1984 (letter)
13. Barthel JS, Westblom TU, Harvey AD, Gonzalez FJ, Everett ED: Pyloric Campylobacter-like organisms in asymptomatic volunteers. Gastroenterology 90:1338, 1986 (abstract)

14. Marshall BJ: Nervous dyspepsia. Med J Aust 142:704, 1984 (letter)

15. Marshall BJ: Peptic ulcer: An infectious disease? Hosp Pract $22: 87-96,1987$

16. Wegener M, Borsch G, Schaffstein J, Schultz-Flaake C, Mai $\mathrm{U}$ : Does gastric Campylobacter pylori colonization cause delay of gastric emptying in non-ulcer dyspepsia? Gastroenterology 94:A490, 1988 (abstract)

17. Prakash C, Marshall BJ, Plankey MW, Gurrant R, McCallum RW: Gastric emptying of solids in patients with Campylobacter pylori gastritis. Am J Gastroenterol 82:935, 1987 (abstract) 